\title{
Homo Deus: Breve historia del mañana
}

\author{
Yuval Noah Harari
}

Barcelona: Editorial Debate, 2017. 496 páginas.

Cada cierto tiempo surgen intelectuales que ponen en la discusión pública temáticas de gran relevancia para las élites políticas y empresariales, a la vez que generan cierta suspicacia en las cúspides académicas: hacen que se sientan convocadas transversalmente a debatir y reflexionar sobre el porvenir del planeta y la humanidad que lo habita. Es en este contexto que el profesor Yuval Noah Harari pasó de ser un desconocido académico de la Universidad Hebrea de Jerusalén a convertirse en una especie de oráculo o profeta del mañana. Diversos medios lo posicionan como uno de los intelectuales de moda, un rockstar de las famosas charlas TED bajo el lema "ideas que vale la pena difundir", al punto que sus recientes libros son recomendados por el expresidente de Estados Unidos, Barack Obama, el empresario fundador de Microsoft, Bill Gates, y el informático creador de Facebook, Mark Zuckerberg. Un tipo de gurú al que líderes mundiales, como Angela Merkel y Emmanuel Macron, desean consultar y con el cual intercambiar ideas. Hoy por hoy lleva vendidos cerca de quince millones de ejemplares de sus ensayos en todo el mundo. Los más famosos son una trilogía sobre la historia de la humanidad contada sin convencionalismos, en la que encontramos Sapiens, de animales a dioses (Editorial Debate, 2014), el que triunfó primero en Israel en 2011 y luego en todo el mundo, y se convirtió en un best seller internacional tras ser publicado en inglés el año 2014. Actualmente ha sido traducido a unos cincuenta idiomas. Este éxito vino seguido por Homo Deus, breve historia del mañana, libro abordado por la presente reseña. Y, más recientemente, 21 Lecciones para el siglo XXI (Editorial Debate, 2018), en el que reflexiona sobre el mundo actual y realiza advertencias para este siglo.

El libro que reseñamos es una breve historia del mañana ¿o una breve "histeria" del mañana? Esa respuesta corresponde darla a los lectores y a los críticos. Por momentos, al leer cada una de sus páginas, es extraordinario apreciar con evidencia el acelerado progreso de la humanidad, nunca habíamos estado mejor que hoy y los que están naciendo serán los afortunados de presenciar lo que ha sido descrito por los más fantásticos libros de ficción. Piensen un momento en la actualidad, afirma el autor, que la guerra es algo obsoleto. Es más probable quitarse la vida que morir en un conflicto bélico. La hambruna está desapareciendo. Es más habitual sufrir obesidad que pasar hambre. La muerte es solo un problema técnico. Cabe acotar que, descripti- 
vamente, esto se alinea con lo que está en boga en Silicon Valley, a través de autores como Steven Pinker, quien recientemente publicó el libro En defensa de la llustración. Por la razón, la ciencia, el humanismo y el progreso (Paidós, 2018). Este ha sido calificado como un paladín optimista del progreso en el que demuestra, a través de diversos datos, que el mundo es menos violento hoy que en el pasado, que la humanidad nunca estuvo mejor y que el presente tiene muchos elementos para estar optimista. Sin embargo, Harari tiene una visión más crítica del porvenir y de la interpretación de la modernidad.

La propuesta está organizada en cuatro bloques. Una parte inicial, titulada "La nueva agenda humana", que podría ser considerada una introducción. Sin embargo, parece más bien un preludio que dará paso a una intensa ópera respecto del hombre moderno, dividida en tres grandes escenas, cada parte es una acción en la que el Homo Sapiens se ha relacionado con el mundo.

La primera parte es una descripción del pasado y la superación de la miserias de este; el "Homo Sapiens conquista el mundo", quiere alcanzar la inmortalidad, la dicha y la divinidad. Es un hecho que, durante décadas, la sociedad en su conjunto buscó combatir la guerra, las pestes y la hambruna. Pero pareciera que todo está ya bajo control ¿qué es lo que sigue? Estamos ad portas de una nueva agenda de prioridades. En 2010 las hambrunas y la desnutrición mataron alrededor de un millón de personas, mientras que la obesidad mató a tres millones. En 1967 la viruela afectaba todavía a quince millones de personas y mataba a dos millones. En poco más de una década, en 1970 la Organización Mundial de la Salud declaró que la humanidad había ganado y que la viruela se había erradicado por completo. Las pestes son temores del pasado. Este milagro se debe a los progresos sin precedentes de la medicina en el transcurso del siglo XX, que nos ha brindado vacunas, antibióticos, mejoras en la higiene y una infraestructura médica más eficiente. La guerra ya no es algo natural. En 2012 murieron en todo el mundo unos 56 millones de personas, 620 mil producto de la violencia humana, por causa de la guerra 120 mil personas y como víctimas del crimen 500 mil. En cambio, 800 mil se suicidaron y 1,5 millones muriendo de diabetes. Es decir, el azúcar es ahora más peligroso que la pólvora. Por lo tanto, con los males que acongojaban a la humanidad por milenios controlados, los próximos objetivos de la humanidad, plantea el autor, probablemente serán la inmortalidad, la felicidad y la divinidad. Esta podría ser una posible agenda del porvenir, ya que, como afirma el autor, "después de haber reducido la mortalidad debida al hambre, la enfermedad y la violencia, ahora nos dedicaremos a superar la vejez e incluso la muerte. Después de haber salvado a la gente de la miseria abyecta, ahora nos dedicaremos a hacerla totalmente feliz. Y después de haber elevado a la humanidad por encima del nivel bestial de las luchas por la supervivencia, ahora nos dedicaremos a ascender a los humanos a dioses, y a transformar Homo sapiens en Homo Deus". 
La segunda parte, consiste en una profunda reflexión en torno a las creencias y el significativo impulso que la religión humanista brindó, al punto que el "Homo Sapiens da sentido al mundo". Lo hace sacralizando la vida, las emociones y los deseos de los seres humanos. En este apartado el autor explora lógicamente la cuestión de qué tipo de personas crearon el mundo y cómo se convencieron de que no solo dominan el mundo sino también dan sentido a éste. En este ensayo Harari destaca lo revolucionario que fue el invento del dinero y la escritura hace unos cinco mil años para organizar sociedades complejas. Enlaza este invento con un término muy nuevo y actual, el del algoritmo. Los algoritmos, plantea el autor, son una cierta forma de patrón, secuencia de pasos, automatismos. En las sociedades que tienen una escritura, las personas ahora pueden organizarse en redes de trabajo, en las que cada una es solo un pequeño automatismo en un algoritmo mucho más grande. La sociedad en su conjunto y como un algoritmo toma decisiones y actúa de acuerdo con ellas. La burocracia ha hecho de este principio su esencia.

Respecto de la escritura, el autor expone que fue fundamental, ya que con ella se abrieron nuevas posibilidades de difusión, lo que atrajo una variedad de cambios en la coexistencia. Lo escrito hizo más fácil creer en cosas ficticias, especialmente cuando estas constantemente rodeado de escritos o incluso escribiéndolos tú mismo (empleados administrativos, etc.). Si es necesario, incluso la realidad tiene que adaptarse a los documentos acordados (por ejemplo, demarcaciones) o ha sido creada por la confianza ciega en los documentos de una realidad de deseos, lo que llevó a decisiones erróneas con algunos efectos dramáticos (por ejemplo, cálculos de rendimiento). Además, Harari reflexiona y sostiene que la superioridad del hombre sobre otros animales reside en dos características centrales: su capacidad para cooperar en grandes grupos de manera flexible e imaginativa, lo que le permite creer en entidades creadas como el Estado, Dios, el dinero, etc. Estas entidades realmente lo hacen parte de un gran grupo de personas cuya relación es aleatoria. Algunos animales operan en grupos grandes, como hormigas o abejas, pero actúan en un sistema instintivo no flexible, estereotipado. Otros animales, como los chimpancés, pueden trabajar en colaboración flexible, pero en grupos de hasta cincuenta individuos que están familiarizados entre sí. Por lo tanto, mientras el hombre vive en un mundo de símbolos que contienen: lenguaje, pensamiento verbal y matemático, y símbolos acordados como dinero, estado, ejército, etc., existe como un organismo sujeto a las leyes de selección natural y diseñado para continuar adaptándose a la naturaleza. Esta es la base de gran parte del drama humano. La entidad simbólica del hombre, el yo, vive en la prisión orgánica, el organismo, pero no vive con ella en paz, de ahí el deseo de vida eterna, omnipotencia, inteligencia ilimitada y felicidad más allá del placer físico. 
Desde la revolución lingüística, hace aproximadamente setenta mil años, los humanos han vivido en "órdenes imaginarias", como Estados, fronteras, religiones, dinero; todo creado por el hombre para permitir una amplia cooperación entre los diferentes seres humanos. La gran capacidad del hombre para dar sentido a sus acciones y pensamientos le permitió alcanzar sus muchos logros. El humanismo, el culto al hombre, fundado por el hombre mismo, y que colocó al ser humano y su voluntad en la cima de las prioridades globales, al tiempo que establece su estatus como el animal dominante en el mundo, es la religión (según la definición de religión de Harari) que rige desde el siglo XX.

Finalmente, la parte III argumenta que el sueño humanista tiene en sí su propia destrucción. En este augurio el "Homo Sapiens pierde el control." El autor discute las preguntas esenciales sobre si las personas pueden continuar dominando el mundo y darle sentido; cómo la biotecnología y la inteligencia artificial amenazan al humanismo y, por último, qué nueva religión podría reemplazar al humanismo. Por encima de todo, ¿quién o qué heredará la humanidad? Esta parte del libro adquiere un carácter distópico. Harari describe un presente y sobre todo un futuro en el que la humanidad ha perdido el control del mundo y de la vida. El Homo Sapiens ha creado su propio gen destructivo.

Dedica varias páginas a la inteligencia artificial como elemento clave de esta nueva era. Plantea la idea similar a la del científico, quien inicialmente se siente orgulloso de su creación, pero pronto se da cuenta de que ya no puede lidiar con ella, al punto que expone el inicio de una nueva configuración societal, de gran responsabilidad política y social al tratar cuestiones sobre el futuro del trabajo y la cohesión social en la que surgen preguntas tales como: ¿qué pasará con el mercado laboral cuando la inteligencia artificial supere a las personas en la mayoría de las tareas cognitivas y procedimentales? Lo que ya está ocurriendo, o ¿qué impacto político tendrá una nueva clase masiva de personas económicamente inútiles? ¿Qué pasará con las relaciones, las familias y los fondos de pensiones cuando la nanotecnología y la medicina regenerativa logren que las personas superen fácilmente los cien años? ¿Qué pasará con la sociedad humana si la biotecnología nos permite obtener bebés de diseño y crear una brecha sin precedentes entre ricos y pobres? ¿Y qué ocurrirá cuando la inteligencia se desconecte de la conciencia?

En este apartado se plantea, tal vez, el más complejo punto del libro, en el que Harari reconoce que el enigma entre la actividad del cerebro y la existencia de la conciencia aún no se ha resuelto. No obstante, en la base de su pensamiento parece que la transición al Homo Deus se basa en el hecho de que los cambios tecnológicos transformarán este enigma. De hecho pregunta ¿qué es más valioso: la inteligencia o la conciencia? Sin 
embargo, la superioridad del hombre en este contexto no debe medirse precisamente por este tipo de respuesta, ya que inteligencia, por ejemplo, ante una resolución de problemas, no es la característica principal en la que se destaca el hombre por encima de los animales. Muchos animales resuelven los problemas de manera inteligente y, como afirma el propio Harari, si una persona está en una isla con un chimpancé, existe una mayor probabilidad de que el chimpancé sea el que solucione mejor los problemas relacionados con la supervivencia. Por tanto, la superioridad del hombre se expresa en otras habilidades en conjunto. Además de ser el animal más desarrollado en la naturaleza, la superioridad del hombre se manifiesta en las funciones superiores de la conciencia, como la libre elección, la creación de un sistema de valores, la autorrealización, la toma de decisiones, la planificación futura, la aspiración de crear vidas auténticas y significativas más allá de la existencia física del yo. Al respecto, el autor parece plantear ciertas dudas. Cabe decir que las altas funciones de la conciencia están relacionadas con la internalización de la experiencia humana y su interacción con el cerebro. La mente humana no puede desarrollarse sin interactuar con la cultura y la sociedad en la que crecen los seres humanos. No se sabe cómo será posible desarrollar algoritmos que activen un sistema de valores, vida auténtica y significativa, realización personal, etc. No obstante, para Harari, el Homo Deus conservará algunos rasgos humanos esenciales, pero también gozará de capacidades físicas y mentales mejoradas que le permitirán seguir siendo autónomo incluso frente a los algoritmos no conscientes más sofisticados. Puesto que la inteligencia se está escindiendo de la conciencia y se está desarrollando a una velocidad de vértigo, los humanos deben mejorar activamente su mente si quieren seguir en la partida.

En este capítulo el autor ofrece reflexiones complejas, no resueltas y de larga disputa, como la filosofía, y se adentra en terribles predicciones sobre el futuro. Presenta su falta de consideración por uno de los asuntos eternos de la filosofía: el tema de la conexión entre cuerpo y alma. Aquí Harari toma una posición clara con los materialistas, que ven al hombre como un grupo de átomos y moléculas a partir de los cuales se construyen las neuronas, y el comportamiento humano simplemente como el producto de un algo que resulta de un conjunto de partículas y energías. Es común que este tema sea eterno. No se ha decidido hasta el día de hoy y no ha podido resolverse. Pero, aunque es imposible probar que hay un alma, no es difícil probar que cada persona está segura de que él mismo tiene un alma.

De acuerdo con lo anterior, Harari lleva al límite el argumento, de hecho, examina las implicaciones prácticas de ciertos descubrimientos científicos, invalidando o dejando en entredicho el pensamiento liberal, defensor de los mercados libres y las elecciones democráticas, ya que cree que cada humano es un individuo único y valioso, cuyas opciones libres son la fuente última de 
autoridad. Harari es rotundo y expone que en el siglo XXI tres acontecimientos prácticos pueden hacer que estás creencias queden obsoletas:

1. Los humanos perderán su utilidad económica y militar, de ahí que el sistema económico y político deje de atribuirles mucho valor.

2. El sistema seguirá encontrando valor en los humanos colectivamente, pero no en los individuos.

3. El sistema seguirá encontrando valor en algunos individuos, pero estos serán una nueva elite de superhumanos mejorados y no la masa de la población.

Le corresponderá al lector juzgar los argumentos expuestos por el autor y la contundencia de éstos. Lo que es innegable es que cada uno de ellos invita a pensar permanentemente, a preguntarnos seriamente lo que somos y a dónde vamos. Esta extrapolación del futuro de los puntos de vista expuestos por Harari son unos desafíos para las personas comunes y también para quiénes son los encargados de tomar decisiones. Pensar por un momento ¿en qué mundo queremos vivir?

Este libro rastrea la génesis del cosmos, busca entender nuestro condicionamiento actual con el fin permitirnos pensar de maneras mucho más imaginativas nuestro futuro. Decidamos cómo queremos vivir los próximos 50 años. ¿Por qué limitar nuestros horizontes prediciendo una única situación hipotética definitiva? Una cosa es segura, el mundo, nuestro entorno, lo que engloba al universo es extraordinariamente más amplio de lo que pensamos y no somos lo suficientemente conscientes del espectro de opciones existentes. Efectivamente, no se puede predecir el futuro, pero a través de la historia sí podemos esbozar diversas posibilidades. Por lo tanto, como dice Harari, "Todas las predicciones que aparecen en este libro sobre el futuro deben entenderse como una forma de iniciar una discusión sobre el presente".

Roberto Sánchez Fuentes ${ }^{1}$

Chileno. Profesor de Historia y Geografía, Universidad Católica Silva Henríquez. Estudiante de Magíster en Políticas Públicas, Universidad del Desarrollo, Chile. E-mail: robersanfu@gmail.com 